\title{
Functionalization of Polymethylhydrosiloxane Gels with an Allyl Ureido Benzocrown Ether Derivative. Complexation Properties
}

\author{
Gihane Nasr, ${ }^{1}$ Hanan Bestal, ${ }^{1}$ Mihail Barboiu, ${ }^{1}$ Bruno Bresson ${ }^{2}$, Thierry Thami ${ }^{1}$ \\ ${ }^{1}$ Institut Européen des Membranes, ENSCM, Université Montpellier 2, CNRS, CC047, 2 Place Eugène \\ Bataillon, 34090 Montpellier cedex 05, France \\ ${ }^{2}$ Laboratoire de Physique Quantique, ESPCI, CNRS, 10 rue Vauquelin, 75231 Paris cedex 05, France
}

E-mail_address: gihane.nasr@iemm.univ-montp2.fr, mihai.barboiu@iemm.univ-montp2.fr, bruno.bresson@espci.fr, thierry.thami@iemm.univ-montp2.fr

Corresponding author: Thierry Thami, Institut Européen des Membranes, Université Montpellier 2, CNRS, ENSCM, CC047, 2 Place Eugène Bataillon, 34095 Montpellier cedex 5, France (thierry.thami@iemm.univ-montp2.fr) 


\section{ABSTRACT}

Crosslinked polymethylhydrosiloxane (PMHS) thin films prepared by sol-gel polycondensation have been functionalized by Pt-catalyzed hydrosilylation of $\mathrm{SiH}$ groups with an allyl ureido crown ether precursor. To this purpose, both 4'-allylurea-benzo-15-crown-5 (1) and 1-allyl-3-propyl-urea (2) were synthesized and characterized. We have shown that competitive side-reactions occurred following hydrosilylation due to the hydrolysis of part of the $\mathrm{SiH}$ groups resulting in the formation of new crosslinks $\mathrm{Si}\left(\mathrm{CH}_{3}\right) \mathrm{O}_{3 / 2}$ as shown by solid-state ${ }^{29} \mathrm{Si}$ NMR. This is explained by the deactivation of the Pt catalyst toward hydrosilylation by amide groups. For thin films $(\sim 1 \mu \mathrm{m})$ prepared on silicon wafers, a quantitative method based on FT-IR transmission spectroscopy was used to measure the crosslinking density of the network, and the percentage of functionalization $(\mathrm{SiC} \%)$ following hydrosilylation. The results are discussed in relation to the mesh size of the network, and the diffusion of alkenes and water molecules within lightly crosslinked PMHS gels obtained by varying the amount of triethoxysilane crosslinker (mol \%) from 15 to $1 \%$. The self-organization properties of ureido groups by H-bonding were studied by FT-IR for the functionalized thin films. The complexation properties of the crown ether 1-functionalized thin films were evidenced by using FT-IR following diffusion-reactions of NaSCN and $\mathrm{KSCN}$ salts in $\mathrm{CHCl}_{3}: \mathrm{MeOH}$ solvent mixtures within thin films.

Keywords: crosslinking, silicones, crown ether, hydrosilylation, functionalization of polymers 


\section{INTRODUCTION}

The surface modification of a solid substrate by the chemical attachment of a polymer is of great importance for altering the interfacial and wetting and adhesion properties in many applications including membranes, sensors, and biomedical devices. ${ }^{1-6}$ Methods for surface modification with alkoxysilane reagents as coupling agents are particularly interesting because they provide strong covalent bonding with the silica surface via siloxane groups. ${ }^{6,7}$

In order to achieve a reactive polysiloxane coating that can be thereafter easily functionalized and adapted for applications, polymethylhydrosiloxane-like (PMHS) polymers have been crosslinked by the sol-gel process allowing subsequent postfunctionalization by hydrosilylation of the $\mathrm{SiH}$ active groups. ${ }^{8,9}$ The PMHS polymer was prepared by acid-catalyzed hydrolytic copolycondensation of a mixture of methyldiethoxysilane $\mathrm{HSiMe}(\mathrm{OEt})_{2}$ monomer and triethoxysilane $\mathrm{HSi}(\mathrm{OEt})_{3}(\mathrm{TH})$ as crosslinker. Among the various curing methods for preparing crosslinked silicones, ${ }^{10,11}$ the sol-gel process allows a facile and rapid formation of $\mathrm{T}^{\mathrm{H}}$-crosslinked PMHS film by complete silanol condensation of $\mathrm{SiH}$ alkoxide precursors at room temperature. ${ }^{8,12-14}$ In addition, crosslinking and surface attachment of the polymer on silica take place in one step.

Hydrosilylation, the addition of hydrosilane $\mathrm{Si}-\mathrm{H}$ groups to carbon-carbon multiple bond, which is generally an alkene $\mathrm{C}=\mathrm{C}$, is a very effective reaction in the bulk, or in solution by using platinum catalysts. ${ }^{15-17}$ Various SiH containing polymer films were introduced into silica powders or particles to alter the surface by subsequent hydrosilylation. Peseck ${ }^{18,19}$ and Brook $^{20}$ reported the reaction of the triethoxysilane coupling agent $\mathrm{TH}$. On other hand, Fukui et $\mathrm{al}^{21,22}$ reported the use of 1,3,5,7tetramethyl-cyclotetrasiloxane. A similar strategy has been developed to alter the surface of silicon elastomers, poly(dimethylsiloxane), including the introduction of $\mathrm{SiH}$ group for subsequent hydrosilylation. ${ }^{23-25}$ In general, hydrosilylation involves steric hindrance and, therefore, can lead frequently to incomplete conversion of the Si-H. New methods that allow control of the accessibility of $\mathrm{SiH}$ groups are thus of interest. 
We are interested in materials containing ureido crown ethers having self-organization properties for recognition and membrane transport based functions. ${ }^{26-28}$ Crown ethers immobilized in organic polymers, have also been widely used for the separation of cation mixtures, ${ }^{29-32}$ and as sensors. ${ }^{33,34}$

We reported previously the preparation of lightly crosslinked PMHS gels for subsequent hydrosilylation with olefins. ${ }^{9}$ In this paper, we extended the study to hydrosilylation with an heteroditopic crown ether receptor 4'-allylurea-benzo-15-crown-5 (1). Since the self-organization properties have been reported elsewhere for the parent compounds ureido crown ether bearing alkyl chains, ${ }^{26,28}$ and for hydrid-organic precursors of thin layer membranes, ${ }^{27}$ we looked for the occurrence of such self-organization within lightly crosslinked PMHS during hydrosilylation with $\mathbf{1}$. For the sake of comparison, 1-allyl-3-propyl-urea (2) was also synthesized and used for hydrosilylation of PMHS.

We describe first the characterization of the allyl urea derivatives $\mathbf{1}$ and $\mathbf{2}$, and the corresponding thin films prepared by hydrosilylation of lightly crosslinked PMHS networks. Then, the reactions in PMHS gel and the hydrosilylation reactions are analyzed as a function of the crosslinking density by varying the concentration of $\mathrm{TH}$ crosslinker from $15 \%$ to $1 \%$. Functionalized PMHS gels as particles after grinding the gel structure were characterized by ${ }^{29} \mathrm{Si}$ solid-state NMR. IR spectroscopy was used to analyze the hydrosilylation reactions in thin films, as well as the self-organization and complexation properties.

\section{EXPERIMENTAL}

\section{Synthesis of alkene precursors}

\section{Solvents, reagents and analytical methods}

All the reagents were obtained from Aldrich (Germany) and used without further purification. The solvents $\mathrm{CH}_{3} \mathrm{CN}$ and petroleum ether were of synthesis grade purity. ${ }^{1} \mathrm{H}$ and ${ }^{13} \mathrm{C}$ NMR spectra were recorded with an ASX $300 \mathrm{MHz}$ Bruker spectrometer (Karlsruhe, Germany); $\delta$-values are in ppm relative to $\mathrm{SiMe}_{4}\left({ }^{1} \mathrm{H}\right.$ and $\left.{ }^{13} \mathrm{C}\right)$. Abbreviations: s, singlet; d, doublet, t, triplet; m, complex multiplet; 
brs, broad singlet; dt, doublet of triplets; ddt, doublet of doublets of triplets. Mass spectrometric analyses were performed by using a quadrupole mass spectrometer Platform IIE (Waters-Micromass, Manchester, England) operated in a positive electrospray ionization mode (ESI+) following the methodology previously described. ${ }^{26}$ IR spectra were recorded with a Nexus FTIR spectrometer (Thermo Nicolet, Madison, WI) by using the dried $\mathrm{KBr}$ pellet technique. Abbreviations: sh, shoulder. The structures and the reactions used to synthesize the alkenes $\mathbf{1}$ and $\mathbf{2}$ from commercial precursors are shown in Figure 1.

\section{4'-Allylurea-benzo-15-crown-5 (1)}

1 was prepared using a similar procedure to that described by Cazacu et $\mathrm{al}^{26}$ by refluxing allyl isocyanate and 4'-aminobenzo-15-crown-5 in $\mathrm{CH}_{3} \mathrm{CN}$ (Fig. 1). Allyl isocyanate (0.31 ml, $3.5 \mathrm{mmol}$ ) was heated under reflux with 4'-aminobenzo-15-crown-5 (1 g, $3.5 \mathrm{mmol})$ in $\mathrm{CH}_{3} \mathrm{CN}$ (30 ml) overnight to afford, after crystallization in $\mathrm{CH}_{3} \mathrm{CN}, \mathbf{1}$ as a white powder $(0.687 \mathrm{~g})$. Yield: $51 \%$. The ${ }^{1} \mathrm{H},{ }^{13} \mathrm{C}$ NMR, and ESI+ MS spectra are in agreement with the proposed formula. ${ }^{1} \mathrm{H}$ NMR $\left(300 \mathrm{MHz}, \mathrm{CDCl}_{3}, \mathrm{ppm}\right) \delta$ $3.72\left(\mathrm{~m}, 8 \mathrm{H},-\left(\mathrm{OCH}_{2} \mathrm{CH}_{2}\right)_{2}-\right), 3.88-3.79$ (m, 4H, $\left.\mathrm{Ar}-\mathrm{OCH}_{2} \mathrm{CH}_{2} \mathrm{O}-\right), 4.09-4.04$ (m, 4H, Ar- $\left.\mathrm{OCH}_{2} \mathrm{CH}_{2} \mathrm{O}\right)$, $4.98\left(\mathrm{t},{ }^{3} J=5.5 \mathrm{~Hz}, 1 \mathrm{H}, \mathrm{NH}-\mathrm{Alkyl}\right), 5.07\left(\mathrm{~d},{ }^{3} J=10-11 \mathrm{~Hz}, 1 \mathrm{H}\right.$, vic. $\left.C H_{2}=\mathrm{CH}-\right), 5.13\left(\mathrm{~d},{ }^{3} J=17-18\right.$ $\mathrm{Hz}, 1 \mathrm{H}$, gem. $\left.\mathrm{CH}_{2}=\mathrm{CH}-\right), 5.9-5.8\left(\mathrm{~m}, 1 \mathrm{H}, \mathrm{CH}_{2}=\mathrm{CH}-\right), 6.49(\mathrm{~s}, 1 \mathrm{H}, \mathrm{NH}-\mathrm{Ar}), 6.66\left(\mathrm{dd},{ }^{3} \mathrm{~J}=8.4 \mathrm{~Hz},{ }^{4} J=\right.$ $2.1 \mathrm{~Hz}, 1 \mathrm{H}, \mathrm{H}-\mathrm{Ar}), 6.76\left(\mathrm{~d},{ }^{3} \mathrm{~J}=8.4 \mathrm{~Hz}, 1 \mathrm{H}, \mathrm{H}-\mathrm{Ar}\right), 6.93\left(\mathrm{~d},{ }^{4} \mathrm{~J}=2.1 \mathrm{~Hz}, 1 \mathrm{H}, \mathrm{H}-\mathrm{Ar}\right) ;{ }^{13} \mathrm{C}$ NMR $(75$ $\left.\mathrm{MHz}, \mathrm{CDCl}_{3}, \mathrm{ppm}\right) \delta 156.69(\mathrm{C}=\mathrm{O}), 149.49,144.69$ (2 $\left.\mathrm{ArC}\right), 135.62\left(\mathrm{CH}_{2}=\mathrm{CH}-\right), 133.88(1 \mathrm{ArC})$, 115.49 (ArC or $\left.\mathrm{CH}_{2}=\mathrm{CH}-\right), 115.37\left(\mathrm{ArC}\right.$ or $\left.\mathrm{CH}_{2}=\mathrm{CH}-\right), 112.97,107.47(2 \mathrm{ArC}), 70.87,70.71,70.50$, 70.29, 69.90, 69.78, 69.48, $68.52\left(8 \mathrm{OCH}_{2}\right), 42.55\left(-\mathrm{CH}_{2}-\mathrm{CH}=\mathrm{CH}_{2}\right) . \mathrm{IR}\left(\mathrm{KBr}\right.$ matrix, $\left.\mathrm{cm}^{-1}\right)$ 3299, 3199, and $3139(\mathrm{NH}), 3078\left(\mathrm{CH}_{2}\right.$ allyl), $3010\left(\mathrm{CH}_{2}+\mathrm{CH}\right.$ allyl $)$ 2929, 2907, and $2870\left(\mathrm{CH}_{2}\right.$ alkyl), 1690, 1660 sh, and $1638(\mathrm{C}=\mathrm{O}$, amide $\mathrm{I}+\mathrm{C}=\mathrm{C}$ allyl), 1606 ( $\mathrm{C}=\mathrm{C}$ aromatic), 1553 and 1512 (NH, amide II), 1455 $\left(\mathrm{CH}_{2}\right), 1299,1261$, and 1216 (CN, amide III), 1129 (COC crown ether), 993 (CH allyl). ESI+ MS: $\mathrm{m} / z$ (relative intensity \%): calcd for $\mathrm{C}_{18} \mathrm{H}_{26} \mathrm{~N}_{2} \mathrm{O}_{6} 366.18$; found $389.32(100 \%)[\mathrm{M}+\mathrm{Na}]^{+}$. 


\section{1-Allyl-3-propyl-urea (2)}

2 was prepared from allylamine and propyl isocyanate (Fig. 1). To a stirred solution of allylamine $(0.15 \mathrm{ml}, 2 \mathrm{mmol})$ in anhydrous petroleum ether $(10 \mathrm{ml})$ was added propyl isocyanate $(0.187 \mathrm{ml}, 2$ mmol). After stirring at room-temperature for $1 \mathrm{~h}$, a white solid was obtained. The reaction mixture was then allowed to proceed under reflux overnight. The solid which separated on cooling was crystallized twice from petroleum ether to afford 2 as a white solid ${ }^{35}(0.258 \mathrm{~g})$. Yield: $91 \%$. The ${ }^{1} \mathrm{H},{ }^{13} \mathrm{C}$ NMR, and ESI+ MS spectra are in agreement with the proposed formula. ${ }^{1} \mathrm{H} \mathrm{NMR}\left(300 \mathrm{MHz}, \mathrm{CDCl}_{3}, \mathrm{ppm}\right) \delta 0.88$ $\left(\mathrm{t},{ }^{3} \mathrm{~J}=7.2 \mathrm{~Hz}, 3 \mathrm{H}, \mathrm{CH}_{3}\right), 1.48\left(\right.$ sextet $\left.,{ }^{3} J=7.2 \mathrm{~Hz}, 2 \mathrm{H}, \mathrm{CH}_{2}\right), 3.09\left(\mathrm{t},{ }^{3} \mathrm{~J}=7.2 \mathrm{~Hz}, 2 \mathrm{H}, \mathrm{CH}_{2}\right), 3.76\left(\mathrm{dt},{ }^{3} J\right.$ $\left.=5.4 \mathrm{~Hz},{ }^{4} \mathrm{~J}=1.6 \mathrm{~Hz}, 2 \mathrm{H}, \mathrm{CH}_{2}\right), 4.65(\mathrm{brs}, 2 \mathrm{H}, \mathrm{NH}), 5.07\left(\mathrm{ddt},{ }^{3} J=10 \mathrm{~Hz},{ }^{2} J=1.4 \mathrm{~Hz},{ }^{4} \mathrm{~J}=1.4 \mathrm{~Hz}, 1 \mathrm{H}\right.$, vic. $\left.\mathrm{CH}_{2}=\mathrm{CH}-\right), 5.17\left(\mathrm{ddt},{ }^{3} \mathrm{~J}=17 \mathrm{~Hz},{ }^{2} \mathrm{~J}=1.6 \mathrm{~Hz},{ }^{4} \mathrm{~J}=1.6 \mathrm{~Hz}, 1 \mathrm{H}\right.$, gem. $\left.\mathrm{CH}_{2}=\mathrm{CH}-\right), 5.82\left(\mathrm{ddt},{ }^{3} \mathrm{~J}=17\right.$ $\left.\mathrm{Hz},{ }^{3} \mathrm{~J}=10 \mathrm{~Hz},{ }^{3} \mathrm{~J}=5.4 \mathrm{~Hz}, 1 \mathrm{H}, \mathrm{CH}_{2}=\mathrm{CH}-\right) ;{ }^{13} \mathrm{C} \mathrm{NMR}\left(75 \mathrm{MHz}, \mathrm{CDCl}_{3}, \mathrm{ppm}\right) \delta 158.89(\mathrm{C}=\mathrm{O}), 135.66$ $\left(\mathrm{CH}_{2}=\mathrm{CH}-\right), 115.77\left(\mathrm{CH}_{2}=\mathrm{CH}-\right), 43.17 \quad\left(-\mathrm{CH}_{2}-\mathrm{CH}=\mathrm{CH}_{2}\right), 42.46 \quad\left(-\mathrm{CH}_{2}-\mathrm{CH}_{2}-\mathrm{CH}_{3}\right), 23.59$ ($\left.\mathrm{CH}_{2}-\mathrm{CH}_{2}-\mathrm{CH}_{3}\right), 11.53\left(\mathrm{CH}_{3}\right)$. IR (KBr matrix, $\left.\mathrm{cm}^{-1}\right) 3342$ and $3140(\mathrm{NH}), 3084\left(\mathrm{CH}_{2}\right.$ allyl), $3009\left(\mathrm{CH}_{2}\right.$ + $\mathrm{CH}$ allyl), $2964\left(\mathrm{CH}_{3}\right), 2934$ and $2875\left(\mathrm{CH}_{2}\right), 1640$ sh $(\mathrm{C}=\mathrm{C}$ allyl $), 1628(\mathrm{C}=\mathrm{O}$, amide $\mathrm{I}), 1585$ and 1535 (NH, amide II), 1465 ( $\mathrm{CH}_{2}$ alkyl), 1419 (CH allyl), 1261 (CN, amide III), 990 and 914 (CH allyl). ESI+ MS: $m / z$ (relative intensity \%): calcd for $\mathrm{C}_{7} \mathrm{H}_{14} \mathrm{~N}_{2} \mathrm{O} 142.11$; found $307.28(100 \%)[2 \mathrm{M}+\mathrm{Na}]^{+}$.

\section{Thin films preparation}

\section{Solvents and reagents}

Both the precursors methyldiethoxysilane $\mathrm{HSi}\left(\mathrm{CH}_{3}\right)\left(\mathrm{OCH}_{2} \mathrm{CH}_{3}\right)_{2}$ (DH) and triethoxysilane $\mathrm{HSi}\left(\mathrm{OCH}_{2} \mathrm{CH}_{3}\right)_{3}(\mathrm{TH})$ were purchased from ABCR (Karlsruhe, Germany) and used as received. Water used for cleaning the substrates was obtained with a Milli-Q water purification apparatus (Millipore). Absolute ethanol for sol-gel synthesis was dried over $4 \AA$ molecular sieve. The catalyst trifluoromethanesulfonic acid $\mathrm{CF}_{3} \mathrm{SO}_{3} \mathrm{H}$ (Aldrich) was dissolved in absolute ethanol $1 \mathrm{M}$. All solvents were of synthesis grade purity. Toluene used for thin film hydrosilylation was dried with calcium hydride and distilled before use. The platinum-divinyltetramethyldisiloxane complex in xylene (PC072) 
(platinum concentration of about $0.1 \mathrm{M}$ assuming $2.4 \% \mathrm{Pt}$ in xylene), also known as Karstedt's catalyst, and hexachloroplatinic (IV) acid hexahydrate $\mathrm{H}_{2}\left[\mathrm{PtCl}_{6}\right]\left(\mathrm{H}_{2} \mathrm{O}\right)_{6}$ were purchased from ABCR. The Speier catalyst was prepared by dissolving hexachloroplatinic acid $(0.1 \mathrm{~g})$ in 2-propanol $(1 \mathrm{~mL})$.

\section{Substrate Cleaning and Activation}

Silicon wafers $\mathrm{Si}(100)$ (MEMC Electronic Materials, Italy) being cut into rectangular square strips of $2 \times 2 \mathrm{~cm}^{2}$ were used as substrates. To bond covalently the PMHS thin films to native oxide silica (thickness $\sim 2 \mathrm{~nm}$ ), the silicon wafers were first cleaned and activated using the previously described procedure. $^{8}$

\section{Synthesis of Crosslinked PMHS}

PMHS thin films of various crosslinking densities were prepared by room temperature sol-gel polymerization of DH/TH sol mixtures deposited by spin-coating on freshly activated substrates using the previously described procedure ${ }^{9}$ which is summarized as follows. Trifluoromethanesulfonic acid $\mathrm{CF}_{3} \mathrm{SO}_{3} \mathrm{H}$ (1M in absolute ethanol) was used as catalyst $(0.5 \mathrm{mmol} / \mathrm{mol}$ of monomers). The mixture of monomers DH/TH ranging from 85/15 to 99/1 (mol \%) were polymerized at about $4 \mathrm{M}$ concentration in $\mathrm{EtOH}($ molar ratio $[\mathrm{EtOH}] /[\mathrm{Si}]=1)$, with 0.5 equivalent of water (hydrolysis ratio $h=\left[\mathrm{H}_{2} \mathrm{O}\right] /[\mathrm{SiOEt}]=$ 0.5). Subsequently, a fully crosslinked film $(\sim 1 \mu \mathrm{m})$ is obtained by spin-coating the mixture under nitrogen. No uncondensed $\mathrm{SiOH}$ or SiOEt species were found as shown by FTIR spectroscopy. The method gives layers of reproducible homogeneity and thickness in the submicrometer range as measured by both ellipsometry and infrared spectroscopy. Samples synthesized from 85/15, 95/5 and 99/1 DH/TH sols were respectively denoted PMHS85, PMHS95 and PMHS99.

\section{Hydrosilylation with compounds 1 and 2}

Prior to hydrosilylation, the substrates with PMHS thin films were cured at $100{ }^{\circ} \mathrm{C}$ in an oven for $1 \mathrm{~h}$, swollen in $\mathrm{CHCl}_{3}$ at room temperature for $30 \mathrm{~min}$, dried under a stream of nitrogen, and then cured at $100{ }^{\circ} \mathrm{C}$. This washing and drying process removes any oligomeric species trapped in the PMHS network and gives the final densification and thickness of the organic layers as shown by ellipsometry 
measurements. ${ }^{8}$ A comparison of the FTIR spectra of the virgin PMHS thin films after this curing process shows no difference, indicating that the $\mathrm{SiH}$ content and $\mathrm{D}^{\mathrm{H}} / \mathrm{T}^{\mathrm{H}}$ ratio are preserved in thin films and that possible formation of new crosslinks is not observed before the hydrosilylation reaction as shown previously by IR spectroscopy. ${ }^{9}$

In a typical preparation, a substrate functionalized with PMHS95 thin film $(\sim 1 \mu \mathrm{m})$ was placed in a 10 $\mathrm{mM}$ solution of one of the reactants [(1) $18 \mathrm{mg}$; (2) $7.1 \mathrm{mg} ; 0.05 \mathrm{mmol}]$ and Karstedt's catalyst (1 to 5 $\mu \mathrm{L}, 10^{-4}$ to $\left.5 \times 10^{-4} \mathrm{mmol}\right)$ in dry toluene $(5 \mathrm{ml})$ for $2 \mathrm{~h}$ at $60-70{ }^{\circ} \mathrm{C}$. The substrate was finally removed from the reaction mixture and rinsed with toluene (twice) and dichoromethane (twice) to remove any physisorbed material. After the solvent was removed in a stream of nitrogen, the sample was dried in an oven at $100^{\circ} \mathrm{C}$ for $1 \mathrm{~h}$. Under the optimum conditions presented here (concentration of 1-alkene, swelling solvent, times, catalyst etc.), the allyl urea compounds were in about 7.5 fold excess with respect to available $\mathrm{SiH}$ on a grafted PMHS thin film of thickness $1 \mu \mathrm{m}$ and surface $4 \mathrm{~cm}^{2}$ assuming the density of the PMHS layer is about $1 \mathrm{~g} / \mathrm{mL}$. We obtained similar results for the reactant 2 by increasing the concentration from $10 \mathrm{mM}$ to $100 \mathrm{mM}$ as shown by FTIR spectroscopy. Attempts to use the Speier catalyst were unsuccessful. The same procedure was followed with compound $\mathbf{2}$ for the hydrosilylation of PMHS thin films $(\sim 1 \mu \mathrm{m})$ of various crosslinking ratios $\mathrm{TH}(\mathrm{mol} \%)$ from 15 to $1 \%$. For all the samples prepared, no delamination of the surface-attached PMHS films occurred upon functionalization with compounds $\mathbf{1}$ or $\mathbf{2}$. PMHS materials prepared with $\mathbf{1}$ or $\mathbf{2}$ were denoted as $\mathbf{1}$-PMHS or 2-PMHS, respectively.

\section{Characterizations of 1-PMHS and 2-PMHS Thin Films}

Infrared spectra of PMHS layer were recorded on a Nexus FTIR spectrometer with the use of unmodified silicon wafer substrates as the background in the $400-4000 \mathrm{~cm}^{-1}$ ranges. The thickness of the virgin PMHS thin films deposited by spin-coating was measured either by infrared spectroscopy or ellipsometry (Plasmos Ellipsometer SD 2300, München, Germany) as previously described. ${ }^{8,9}$ 
To quantify the SiH conversion from the transmission IR spectra of PMHS thin films, the disappearance of the strong $\mathrm{Si}-\mathrm{H}$ stretching bands $v(\mathrm{SiH})$ of both $\mathrm{DH}$ and $\mathrm{TH}$ subunits was studied by measuring the total integrated absorbances in the $2100-2300 \mathrm{~cm}^{-1}$ region of reacted and unreacted samples. The $\mathrm{SiH}$ residual percentage $(\% \mathrm{SiH})$ given in Table 1 (see later) is then calculated by dividing the integrated absorbance of the reacted sample with that measured before reaction (same sample).

Following hydrosilylation, the percentage of functionalization $(\% \mathrm{SiC})$ can be measured with good sensitivity from the strong absorption of the methylene group, $v_{a s}\left(\mathrm{CH}_{2}\right)$ antisymmetric stretching in the $2935-2915 \mathrm{~cm}^{-1}$ region for alkanes. ${ }^{36}$ For that calculation, we used a previous calibration of $v_{a s}\left(\mathrm{CH}_{2}\right)$ absorption for alkyl-functionalized PMHS95 thin films $(\sim 1 \mu \mathrm{m})$ prepared by hydrosilylation with 1akenes $\mathrm{CH}_{2}=\mathrm{CH}\left(\mathrm{CH}_{2}\right)_{n-2} \mathrm{CH}_{3}$ of various lengths $(n=5$ to 17$){ }^{9}$ The strong $v_{a s}\left(\mathrm{CH}_{2}\right)$ band was found at 2921-2926 cm $\mathrm{cm}^{-1}$ for the various alkyl side chains $\mathrm{Si}\left(\mathrm{CH}_{2}\right)_{\mathrm{n}} \mathrm{CH}_{3}$. The maximum $\mathrm{CH}_{2}$ absorbance $\left(A_{\mathrm{CH}_{2}}\right)$ following hydrosilylation is correlated with the disappearance of the $\mathrm{SiH}$ bands. Further, $A_{\mathrm{CH}_{2}}$ corresponding to fully reacted samples were measured relatively to the $1100-\mathrm{cm}^{-1} \mathrm{SiOSi}$ absorption $\left(A_{S i O}\right)$, or the $2169-\mathrm{cm}^{-1} \mathrm{SiH}$ absorption $\left(A_{S i H}\right)$ of the unreacted PMHS95 (same sample). Based on this measurement, it was found for a complete reaction on $\mathrm{SiH}$ groups that the normalized ratio $\left(\mathrm{A}_{\left.\mathrm{CH}_{2} / \mathrm{A}_{\mathrm{SiO}}\right)}\right.$ or $\left(A_{\mathrm{CH}_{2}} / A_{\mathrm{SiH}}\right)$ increases with the number of methylene group $(n)$ in the hydrocarbon chain $\mathrm{Si}\left(\mathrm{CH}_{2}\right)_{\mathrm{n}} \mathrm{CH}_{3}$ as follows:

$$
\begin{aligned}
& \frac{A_{\mathrm{CH}_{2}}}{A_{\mathrm{SiO}}}=0.207 n \times \mathrm{SiC} \\
& \frac{A_{\mathrm{CH}_{2}}}{A_{\mathrm{SiH}}}=0.284 n \times \mathrm{SiC}
\end{aligned}
$$

where $\mathrm{SiC}=100 \%$ for complete addition of the alkene molecules to the $\mathrm{SiH}$ bonds as well as for the functionalization of the PMHS95 network with alkyl sides chains $n=5$ and 11 .

In the case of the pure allyl urea compounds $\mathbf{1}$ and $\mathbf{2}$, the above equations were validated for spincoated PMHS95 films of $\mathbf{1}$ and $\mathbf{2}$ embedded within the polymer matrix where ' $\mathrm{SiC}$ ' corresponds here to 
the molar fraction of $\mathbf{1}$ or $\mathbf{2}$ in the matrix. The embedded films $(\sim 1 \mu \mathrm{m})$ were prepared on wafer subtrates as follows: Compounds 1 (molar fraction of $6 \% \mathrm{~mol} / \mathrm{mol}$ of $\mathrm{SiH}$ in PMHS95 matrix) or 2 (6 and 23\%) were dissolved in a $\mathrm{DH} / \mathrm{TH} 95 / 5$ sol prepared by using $\mathrm{CHCl}_{3}$ instead of $\mathrm{EtOH}$ as solvent, and deposited by spin-coating. $A_{\mathrm{CH}_{2}}$ of the films with $\mathbf{1}$ and $\mathbf{2}$ and the absorptions were measured at 2921 and 2932.5, respectively, $A_{\mathrm{SiO}}$ at 1100 , and $A_{\mathrm{SiH}}$ at $2169 \mathrm{~cm}^{-1}$. The ratio $\left(A_{\mathrm{CH}_{2}} / A_{\mathrm{SiO} O}\right)$ and $\left(A_{\mathrm{CH}_{2}} / A_{\mathrm{SiH}}\right)$ were in good agreement (accuracy of $\pm 10 \%$ ) with the molar fraction ' $\mathrm{SiC}$ ' of $\mathbf{1}$ or $\mathbf{2}$ given by eqs 1 and 2 , where the number of methylene group is $n=3$ and 9 , respectively.

To quantify $\mathrm{SiC}$ in 1-PMHS and 2-PMHS films in Table 1 (see later), the following values were used: $n=5$ and $n=11$ for the reacted samples 1-PMHS and 2-PMHS, respectively; $A_{\mathrm{CH}_{2}}$ of the reacted samples measured at 2929 and 2931, respectively; $A_{S i O}$ and $A_{S i H}$ measured before the hydrosilylation reaction respectively at $\sim 1100$ and $\sim 2169 \mathrm{~cm}^{-1}$ in the corresponding unreacted samples (virgin PMHS). These quantitative analyses based on IR spectra measurements of thin films can be extended to various 1-alkenes to determine the percentage of functionalization following hydrosilylation.

The complexation study of NaSCN and KSCN salts in 1-PMHS95 and 2-PMHS95 thin films was performed by IR spectroscopy by measuring the absorbance of the characteristic $v(\mathrm{C} \equiv \mathrm{N})$ stretching band of the thiocyanate anion incorporated within the layer as follows. NaSCN and KSCN (Aldrich) dilute solutions $(1 \mathrm{mM})$ were prepared in $\mathrm{CHCl}_{3}: \mathrm{MeOH}$ solvent mixtures of various volumic fractions from 90:4 to 50:50 (v:v), with dry chloroform filtered on aluminium oxide and methanol dried over $4 \AA$ molecular sieve. The samples 1-PMHS95 and 2-PMHS95 were immersed for $30 \mathrm{~min}$ in $5 \mathrm{ml}$ of NaSCN or KSCN solution. The samples were then washed (twice) with the pure solvent mixture to remove any physisorbed salt on the surface. The absorbances of the thiocyanate anion at $2054 \mathrm{~cm}^{-1}$ for KSCN and $2059 \mathrm{~cm}^{-1}$ for NaSCN were then measured by infrared spectroscopy. The process of decomplexation was performed by rinsing the samples in $\mathrm{MeOH}: \mathrm{H}_{2} \mathrm{O}(50: 50)$. The extinction coefficient of the $v(\mathrm{C} \equiv \mathrm{N})$ band $\left(\varepsilon_{\mathrm{C} \equiv \mathrm{N}}\right)$ was calibrated after grinding $\mathrm{NaSCN}$ salt in $\mathrm{KBr}$ matrix $\left(\varepsilon_{\mathrm{C} \equiv \mathrm{N}}=200 \mathrm{M} . \mathrm{cm}^{-1}\right.$; accuracy \pm $20 \%)$. 


\section{Hydrosilylation of PMHS95 Powder with Compound 2}

The PMHS95 powder was prepared from a DH/TH 95/5 mixture after grinding the gel structure, and purified prior to hydrosilylation by Soxhlet extraction with $\mathrm{CCl}_{4}$ using the same procedure as previously described. ${ }^{9}$ The powder particles have a size between 10 to $150 \mu \mathrm{m}$ as observed by scanning electron microscopy. For hydrosilylation with compound 2, the PMHS95 powder $(0.4 \mathrm{~g}, 6.75 \mathrm{mmol})$ was added to a solution of reactant $2(1.92 \mathrm{~g}, 13.5 \mathrm{mmol})$ and Karstedt's catalyst (15 $\left.\mu \mathrm{L}, 1.510^{-3} \mathrm{mmol}\right)$ in toluene $(20 \mathrm{~mL})$. The reaction was allowed to proceed under reflux overnight with magnetic stirring. The final solid was filtered and washed thrice with toluene. After the solvent was removed, the solid was dried at $50{ }^{\circ} \mathrm{C}$ overnight. The starting PMHS95 has rubber-like behavior while the final solid is brittle. The increase in hardness indicates that the crosslinking density increases on hydrosilylation. The solid-state NMR analyses of the powders were performed by using an ASX 500 Bruker spectrophotometer (Karlsruhe, Germany). The experimental conditions that we used for the ${ }^{29} \mathrm{Si}$ MAS techniques are as follows: single-pulse experiment with proton decoupling, 4- $\mu$ s pulse, recycle delay of $30 \mathrm{~s}$, spinning frequency $5 \mathrm{kHz}$, with 500 scans.

\section{RESULTS AND DISCUSSION}

\section{Functionalization of Crosslinked PMHS with Alkenes}

In the first step, a three dimensional silicone network is created via sol-gel reaction of methyldiethoxysilane $\mathrm{HSi}\left(\mathrm{CH}_{3}\right)\left(\mathrm{OCH}_{2} \mathrm{CH}_{3}\right)_{2}$ and triethoxysilane $\mathrm{HSi}\left(\mathrm{OCH}_{2} \mathrm{CH}_{3}\right)_{3}$ as crosslinker. This can be represented as follows:

$$
\begin{aligned}
& \alpha \mathrm{HSi}\left(\mathrm{CH}_{3}\right)\left(\mathrm{OCH}_{2} \mathrm{CH}_{3}\right)_{2}+(1-\alpha) \mathrm{HSi}\left(\mathrm{OCH}_{2} \mathrm{CH}_{3}\right)_{3} \underset{\mathrm{H}_{2} \mathrm{O}}{\stackrel{\mathrm{H}^{+}}{\longrightarrow}}
\end{aligned}
$$

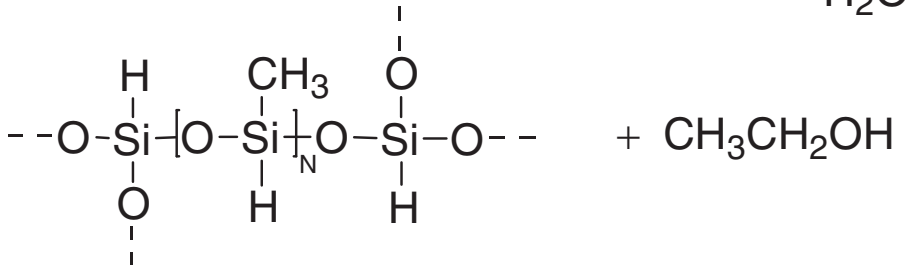


where $\alpha$ is the molar fraction of the $\mathrm{DH}$ monomer. For soft materials, the networked structure was modeled by PMHS chains $-\left(\mathrm{SiHCH}_{3} \mathrm{O}_{2 / 2}\right)_{N^{-}}$between trifunctional crosslink points $\mathrm{SiHO}_{3 / 2}\left(\mathrm{~T}^{\mathrm{H}}\right)$ assuming that all the crosslink points have reacted because $\mathrm{SiOH}$ or SiOEt species were not detected by FTIR or NMR. Details of the FTIR and NMR analyses of thin films and powdered gels have been given elsewhere. ${ }^{8}$ We have shown that the copolymerization of DH/TH mixtures results in homogeneous and fully crosslinked 3D polysiloxane gels. Thus, for the copolymerization of a mixture $\alpha /(1-\alpha)$ of DH/TH, and for trifunctional crosslinks, the average number of repeat unit $N$ between two crosslinkers in PMHS segment is as follows:

$$
N=\frac{2 \alpha}{3(1-\alpha)}
$$

The upper limit mesh size $\xi_{\max }$ of the gel corresponds to fully stretched PMHS chains in the all-trans conformation. Then, assuming uniform distribution of mesh size, for the extended PMHS segments $\left(\mathrm{SiHCH}_{3} \mathrm{O}_{2 / 2}\right)_{N}$ the numerical value of $\xi_{\max }$ is given by:

$$
\xi_{\max }(\AA)=3.12(N+1)
$$

where every $\mathrm{Si}-\mathrm{O}$ subunit contributes $1.56 \AA$ to the mesh size (for an $\mathrm{Si}-\mathrm{O}$ bond length of $1.66 \AA$ and an Si-O-Si angle of $140^{\circ}$ ).

A previous study of the FTIR characteristics and of the Young's moduli of $\mathrm{T}^{\mathrm{H}}$-crosslinked thin films both indicate qualitatively that the number of repeat units between crosslinks $(N)$ increases continuously by decreasing the concentration of $\mathrm{TH}$ crosslinker to as little as $1 \%(\mathrm{~mol} \%) .{ }^{8,9}$ Here, in the elastomeric range, a very little variation of the $\mathrm{TH}$ amount is enough to dramatically change the length of the polymer segment, e. g, $\xi_{\max }$ increases from $43 \AA$ to $209 \AA$ by a factor of about 5 by decreasing TH from $5 \%$ to $1 \%$, respectively. Consequently, for the soft materials prepared with a small amount of $\mathrm{TH}$ additive, the PMHS mesh size $\left(\xi_{\max }\right)$ of the network can be adapted in principle to permit the diffusion of most of the alkenes molecules within the network if their molecular sizes are smaller than $\xi_{\max }$. 
In a second step, the addition of a terminal double bond to the silicon hydride species $\mathrm{P}-\mathrm{SiH}\left(\mathrm{P}=\mathrm{T}^{\mathrm{H}}-\right.$ crosslinked PMHS network) involves reaction between alkenes $\mathbf{1}$ and $\mathbf{2}$ with $\mathrm{Si}-\mathrm{H}$ groups derivatized from both DH and TH subunits as follows:

$$
\mathrm{P}-\mathrm{Si}-\mathrm{H}+\mathrm{H}_{2} \mathrm{C}=\mathrm{CH}-\mathrm{R} \underset{\text { Heat }}{\stackrel{\mathrm{Pt} \text { catalyst }}{\longrightarrow}} \mathrm{P}-\mathrm{Si}-\mathrm{CH}_{2}-\mathrm{CH}_{2}-\mathrm{R}
$$

The alkenes $\mathbf{1}$ and $\mathbf{2}$ are not commercially available but easy to prepare (see Experimental Part). However, because of the cost and effort involved in the preparation of $\mathbf{1}$, the used amounts of reactant for surface derivatization were limited by using dilute $10 \mathrm{mM}$ solution in dry toluene. Toluene was used as solvent for the hydrosilylation reaction because toluene is a good swelling solvent of the organic PMHS polymer and it allows a rapid diffusion of reagents and catalyst into the swollen gel. The hydrosilylation reaction was carried out using an excess of alkenes $\mathbf{1}$ or $\mathbf{2}$ (7.5 equiv) with respect to available $\mathrm{SiH}$ on a spin-coated PMHS thin film $(1 \mu \mathrm{m})$, and two equivalents of alkene 2 for the functionalization of powdered gel (see Experimental section). We used the most common Pt catalyst for hydrosilylation, platinum divinyltetramethyldisiloxane complex, also known as Karstedt's catalyst with a large concentration of $2 \times 10^{-3}$ to $10^{-2} \mathrm{~mol}$ of Pt per mol of alkenes. Only $10^{-7}$ to $10^{-8}$ equiv catalysts are sufficient under ideal conditions to catalyze the reaction. ${ }^{16}$ The hydrosilylation is thus probably complicated (see later) by the presence of heteroatoms other than oxygen such as the amido groups in the allyl urea derivatives $\mathbf{1}$ and $\mathbf{2}$.

\section{Reactions in Crosslinked PMHS Gel}

Figures 2(a) and 3(a) show the transmission IR spectra of the samples obtained after the hydrosilylation reactions with precursors $\mathbf{1}$ and $\mathbf{2}$, respectively, within the lightly crosslinked PMHS95 gel $\left(\xi_{\max }=43 \AA\right)$ as thin films $(\sim 1 \mu \mathrm{m})$. For the sake of comparison, the spectra of the unreacted PMHS95 thin film samples were recorded before hydrosilylation [Figs. 2(b) and 3(b)]. In addition, Figures 2(c) and 3(c) show the spectra of allyl urea precursors $\mathbf{1}$ and 2, respectively, in a $\mathrm{KBr}$ matrix. 
In Figures 2(a) and 3(a), the $v(\mathrm{Si}-\mathrm{H})$ absorption at 2169 and $\delta(\mathrm{SiH})$ absorptions at 891 and 840 almost disappeared, and a $v\left(\mathrm{CH}_{2}\right)$ absorption appeared around 2870 and $2930 \mathrm{~cm}^{-1}$. For 1-PMHS95, the $v\left(\mathrm{CH}_{2}\right)$ stretching corresponds to $\mathrm{CH}_{2}-\mathrm{O}$ group of the macrocyclic crown ether, and $\mathrm{CH}_{2}$ of the newlyformed silyl-propyl group attached to the siloxane network. Similarly for 2-PMHS95, the $v\left(\mathrm{CH}_{2}\right)$ absorption appeared because the silyl-propyl and urea-propyl groups are introduced following hydrosilylation. On the other hand, the following bands assigned to the allyl group disappeared after hydrosilylation: $v(\mathrm{C}=\mathrm{C})_{\text {allyl }}$ around $1640, v\left(\mathrm{CH}_{2}\right)_{\text {allyl }}$ around 3010 and 3085 , and particularly the most characteristic bending $\delta(\mathrm{CH})_{\text {allyl }}$ around $990 \mathrm{~cm}^{-1}$ [Figs. 2(c) and 3(c)]. Furthermore, we observe the characteristic bands associated with the urea groups, $\mathrm{N}-\mathrm{H}$ stretching mode $v(\mathrm{NH}), \mathrm{C}=\mathrm{O}$ stretching vibration $v(\mathrm{C}=\mathrm{O})($ amide $\mathrm{I}), \mathrm{N}-\mathrm{H}$ in-plane bend $\delta(\mathrm{NH})$ (amide II) and $\mathrm{C}-\mathrm{N}$ stretching vibration $v(\mathrm{CN})$ (amide III). Tables 2 and 3 list the major bands for 1-PMHS95 and 2-PMHS95, respectively, and possible assignments are given. All these confirmed that the precursors $\mathbf{1}$ and $\mathbf{2}$ were chemically bonded to the Si atom of the PMHS network.

Based on IR absorption measurements, it was found that the percentage functionalization (\% SiC), as measured independently from the absorption of $v_{a s}\left(\mathrm{CH}_{2}\right)$ antisymmetric stretching (see Experimental section) is lower than expected from the $\mathrm{SiH}$ conversion $(=100 \%-\% \mathrm{SiH}$ residual) (Table 1). This suggests that a part of the $\mathrm{SiH}$ groups undergoes a Pt-catalyzed hydrolysis where $\mathrm{SiH}$ is hydrolyzed into a silanol according to the reaction:

$$
\mathrm{P}-\mathrm{Si}-\mathrm{H}+\mathrm{H}_{2} \mathrm{O} \stackrel{\text { Pt catalyst }}{\longrightarrow} \mathrm{P}-\mathrm{Si}-\mathrm{OH}+\mathrm{H}_{2}
$$

Further, new $\mathrm{Si}-\mathrm{O}-\mathrm{Si}$ crosslinks occur when the newly-formed silanol groups react with the remaining silicon-bonded hydrogen, according to the Pt-catalyzed dehydrocoupling reaction of $\mathrm{SiOH} / \mathrm{SiH}$ :

$$
\mathrm{P}-\mathrm{Si}-\mathrm{H}+\mathrm{HO}-\mathrm{Si}-\mathrm{P} \stackrel{\mathrm{Pt} \text { catalyst }}{\longrightarrow} \mathrm{P}-\mathrm{Si}-\mathrm{O}-\mathrm{Si}-\mathrm{P}+\mathrm{H}_{2}
$$

Another possible chemical reaction is the $\mathrm{SiOH}$ condensation between different molecules: 


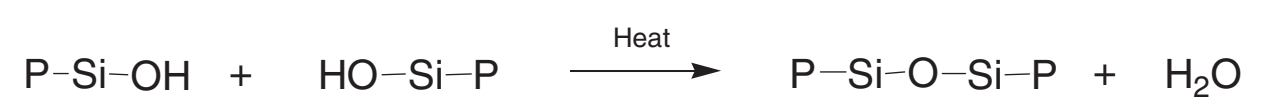

These side-reactions are significant because the amide group of urea precursors probably inhibits the primary hydrosilylation (5).

The formation of new crosslinks was confirmed both by solid-state NMR (see later) and IR spectroscopy. Indeed, IR spectra of thin films following hydrosilylation showed a significant increase $(30-50 \%)$ in the absorption bands characteristic of the asymmetric stretching of the $\mathrm{Si}-\mathrm{O}-\mathrm{Si}$ bonds at 1025-1100 $\mathrm{cm}^{-1}$ by comparison with the starting PMHS95 samples [Figs. 2 and 3]. In Table 1, an evaluation of the percentage of new crosslinks was attempted by subtracting the $\mathrm{SiH}$ conversion (\%) from $\mathrm{SiC}(\%)$. The secondary reactions (6)-(8) would consequently increase the degree of crosslinking of the PMHS matrix from 5\%, for the starting PMHS95, to about 75 and 65\% estimated for the functionalized films 1-PMHS95 and 2-PMHS95, respectively (Table 1). By comparison, when the crosslinking ratio $\mathrm{TH}(\%)$ of the starting PMHS gel increased from 5 to $50 \%$, the absorption coefficient $\alpha_{\mathrm{SiO}}$ calibrated at $1100 \mathrm{~cm}^{-1}$ increased by about $30 \%$ due to the higher density of the SiO vibrational groups in the higher crosslinked gel. ${ }^{8}$ This confirms that the relative increase of the SiOSi band absorption following hydrosilylation $(30-50 \%)$ is in agreement with the degree of crosslinking of 1PMHS95 and 2-PMHS95 films estimated in Table 1.

Further hydrosilylation of PMHS95 powdered after grinding the gel structure was performed with compound 2 to confirm reactions (5)-(8) in PMHS gel. Figures 4(a) and 4(b) show the solid-state ${ }^{29} \mathrm{Si}$ NMR spectra of the 2-functionalized PMHS95 and starting PMHS95 powders, respectively, and the percentage of each silicon units are given in Table 4. In Figure 4(a), there is the appearance of a broad signal at $-21.2 \mathrm{ppm}\left(9 \%\right.$ of the total amount of silicon units) characteristic of an (alkyl) $\mathrm{SiCH}_{3} \mathrm{O}_{2 / 2}$ environment for $\mathrm{D}_{2}$ subunits in linear polysiloxane segments. This clearly demonstrates the functionalization of powder particles following hydrosilylation. Similarly, the decrease of the $\mathrm{T}_{3}{ }^{\mathrm{H}}$ 
$\left(\mathrm{SiHO}_{3 / 2}\right)$ signal (about $2 \%$ ) following hydrosilylation indicates a possible reaction with the crosslinker subunits (Table 4).

The residual $\mathrm{SiH}$ signal in 2-PMHS95 is found at -35 for $\mathrm{D}_{2}{ }^{\mathrm{H}}\left(\mathrm{SiHCH}_{3} \mathrm{O}_{2 / 2}\right)$ subunits and at $-85 \mathrm{ppm}$ for $\mathrm{T}_{3}{ }^{\mathrm{H}}$ crosslinker subunits. By adding both integrated signals $\mathrm{D}_{2}{ }^{\mathrm{H}}$ and $\mathrm{T}_{3}{ }^{\mathrm{H}}$, we estimated that a large proportion of silicon-bonded hydrogen $(\mathrm{SiH} 66 \%)$ remained in the powder particles after reaction in comparison with the 2-PMHS95 thin film ( $\mathrm{SiH} 5 \%$ ) (Table 1). This suggests that the diffusion of the alkenes reagents into the particle core is limited by the larger average size of particles $(10-150 \mu \mathrm{m})$ and by the higher degree of crosslinking (see later) than for the as-prepared thin film.

Furthermore, the decrease of $\mathrm{D}_{2}{ }^{\mathrm{H}}$ following hydrosilylation (24\%) is higher than expected from integration of the newly-formed $\mathrm{D}_{2}(9 \%)$ (Table 4). As shown earlier for thin films, this suggests that hydrolysis of a part of the SiH groups in PMHS segment $\left(\mathrm{D}_{2}{ }^{\mathrm{H}}\right)$ occurred following the secondary reactions (6)-(8) to give new crosslinks $\mathrm{CH}_{3} \mathrm{SiO}_{3 / 2}\left(\mathrm{~T}_{3}\right)$. This is confirmed by an intense and broad signal at $-65 \mathrm{ppm}(22 \%)$ characteristic of the $\mathrm{T}_{3}$ environment, and a small signal (2\%) at $-57 \mathrm{ppm}$ characteristic of $\mathrm{HOSiCH}_{3} \mathrm{O}_{2 / 2}\left(\mathrm{~T}_{2}{ }^{\mathrm{OH}}\right)$. As expected, the decrease of mobility of silicon units in 2PMHS95 following the increase of the degree of crosslinking during reactions (6)-(8) is confirmed by broad signals for all silicon units [Fig. 4(a)] in comparison with the starting PMHS95 spectrum [Fig. 4(b)].

Taking into account the presence of some $\mathrm{T}_{3}$ crosslinking points $(7 \%)$ in the as-prepared starting PMHS95 powder, we estimated the amount of newly-formed crosslinks following the hydrosilylation reaction to be about $15 \%$ (Table 1). This value is lower than that measured for thin films $(65 \%)$ because hydrolysis of $\mathrm{SiH}$ occurs probably near the top of the surface by diffusion of water from the reaction medium or from atmosphere into the hydrophobic PMHS matrix; this process being limited for powder particles because their size of $10-150 \mu \mathrm{m}$ is higher than thin films of $\sim 1 \mu \mathrm{m}$ thickness.

Another explanation for the lower reactivity of PMHS95 powder toward hydrosilylation than the corresponding thin films is that the as-prepared PMHS95 has a higher degree of crosslinking due to the 
presence of $\mathrm{T}_{3}$ crosslinks (7\%) which limits the diffusion process of the reactants. Indeed, from eqs 3 and 4 , it can be shown that the calculated average mesh size of the starting network dramatically decreases when the degree of crosslinking varied from 5 to $13 \%$ by assuming the molar fraction of crosslinker $1-\alpha$ is the sum of $\mathrm{T}_{3}{ }^{\mathrm{H}}$ and $\mathrm{T}_{3}$ crosslinks. The $\mathrm{T}_{3}$-crosslinking occurred resulting from the presence of moisture during the reaction of the alkoxide precursors and drying of the gel. ${ }^{8}$ In constrat to the powder, we have shown that the $\mathrm{SiH}$ functions are preserved in the PMHS thin films because the process of gelification and solvent drying is done quickly under nitrogen during the preparation of films by spin-coating. ${ }^{9}$ The presence of $\mathrm{T}_{3}$ crosslinks before hydrosilylation is thus probably negligible for thin films.

\section{Effect of the Degree of Crosslinking of PMHS Gels}

The degree of crosslinking determines the extent of swelling, the effective pore size of the gel, the penetration of the reagent within the PMHS network for complete hydrosilylation, and in turn these properties determines the facility of functionalization of PMHS gels. Therefore, by decreasing the crosslinking ratio $(\% \mathrm{TH})$ of a series of starting PMHS gels from 15 to $1 \%$ (Table 1), we expected that hydrosilylation would be easier because the diffusion of alkene molecules is facilitated. For instance, both PMHS95 and PMHS99 starting gels have a calculated mesh size $\xi_{\max }$ larger than the molecular size of the alkene precursors 1 or 2 , i.e., $\xi_{\max }=43$ and $210 \AA$, respectively from eqs 3 and 4 .

A significant increase of the ratio of functionalization $(\mathrm{SiC}=0.45)$ is observed on hydrosilylation with alkene 2 for the lowest crosslinked gel of the series (PMHS99; $\xi_{\max } \approx 210 \AA$ ), while SiH groups fully disappeared (Table 1). However, hydrosilylation reaction (5) does not occurred fully as expected. The final degree of crosslinking of the gel, which was estimated to be about $55 \%$ corresponds to $\xi_{\max } \approx 5 \AA$ which is lower than the size of the alkene. Therefore, even if the mesh size of the starting PMHS99 is much larger than the size of the alkene precursor, the functionalization is limited because the sidereactions (6)-(8) also increase the degree of crosslinking of the gels during hydrosilylation (5). 
In contrast, the functionalization of PMHS95 gels with olefins bearing long alkyl side chain (e.g. dodecyl or octadecyl) was almost complete by hydrosilylation under similar conditions. ${ }^{9}$ This confirms that the urea groups in alkenes $\mathbf{1}$ and $\mathbf{2}$ probably deactivate Pt catalyst toward the primary hydrosilylation reaction (5). For the olefins, the side-reactions (6)-(8) are insignificant because the rate of the primary hydrosilylation reaction (5) was higher given the concentration of the alkene and catalyst used. For the urea precursors, the self-assembly property of ureido groups which direct the formation of the network structure by hydrogen bonding $\mathrm{NH} \ldots \mathrm{O}=\mathrm{C}$ (see later) must also play a role because the crosslinking density increases with the association of the urea groups.

By using the benzocrown ether $\mathbf{1}$, the best results were also obtained for the lightly crosslinked PMHS95 $(\mathrm{SiC}=0.15)$. No significant effect was found by using PMHS99 gel. As expected, the ratio of functionalization $\mathrm{SiC}$ is lower than for the compound $\mathbf{2}$ because of the higher molecular size of the alkene precursor 1. In addition to the above, other factors including solvent, swelling, polarity and compatibility of the alkene reactant with the PMHS polymer are also probably important parameters regarding network reactivity toward hydrosilylation.

\section{Association of Urea Groups in Functionalized PMHS Gels}

The various positions of the $v(\mathrm{NH}), v(\mathrm{CO})$ and $\delta(\mathrm{NH})$ bands for 1- and 2-PMHS95 thin films show that intermolecular association of the urea groups by hydrogen bonding $\mathrm{NH} \ldots \mathrm{O}=\mathrm{C}$ occurs in the polymer matrix as in the pure crystalline solid state (Table 2 and 3 ).

For crown ether in 1-PMHS95 matrix, the stretching frequencies $v(\mathrm{NH})$ and $v(\mathrm{CO})$, centered at 3340 and $1647 \mathrm{~cm}^{-1}$, respectively, confirm the existence of a strong association between urea groups of different molecules by H-bonding. By comparison, these peaks are slightly shifted at 3320 and $1635 \mathrm{~cm}^{-}$

${ }^{1}$ for the hybrid materials obtained upon hydrolysis of ureido benzocrown ether triethoxysilane precursors, ${ }^{27}$ indicating that the strength of the H-bonding is similar. This suggests that the density of functionalization of the PMHS film near the top of the surface is probably higher than in the bulk. It is 
noteworthy that the free $v(\mathrm{NH})$ bond of urea group ${ }^{37}$ is also detected in 1-PMHS95 [Fig. 2(a)] by a large band at $\sim 3400-3500 \mathrm{~cm}^{-1}$.

For the 2-PMHS95 matrix the stretching frequencies $v(\mathrm{NH})$ and $v(\mathrm{CO})$ are centered at 3340 and 1636 $\mathrm{cm}^{-1}$, respectively, indicating that the strength of the H-bonding is similar to 1-PMHS95. However, the free $v(\mathrm{NH})$ bond of urea group is not detected [Fig. 3(a)]. This can be explained by the higher density of functionalization of the PMHS95 gel for precursor $\mathbf{2}(\mathrm{SiC}=0.30)$ than for $\mathbf{1}(\mathrm{SiC}=0.15)$.

Whereas a crystalline material was previously obtained upon hydrolysis of an ureido benzocrown ether triethoxysilane precursor in the solid state, ${ }^{27}$ the formation of a three-dimensional crystallized supramolecular structure was not observed here by X-ray diffration. This is probably due to the effect of the crosslinking reactions in the PMHS matrix which occurs during the course of the hydrosilylation reaction.

\section{Complexation Study by IR Spectroscopy}

The formation of $\mathrm{Na}^{+}$and $\mathrm{K}^{+}$complexes was shown by infrared spectroscopy for the 1-PMHS95 thin film functionalized with the benzocrown ether derivative. Indeed, the $v(\mathrm{C} \equiv \mathrm{N})$ stretching band of thiocyanate incorporated in the 1-PMHS95 layer appears respectively at $2054 \mathrm{~cm}^{-1}$ for KSCN and 2059 $\mathrm{cm}^{-1}$ for $\mathrm{NaSCN}$ by immersing the sample in dilute $1 \mathrm{mM}$ nonaqueous $\mathrm{CHCl}_{3}: \mathrm{MeOH}$ solutions of $\mathrm{NaSCN}$ or KSCN salt (see experimental part). By calibration of the $v(\mathrm{C} \equiv \mathrm{N})$ peak, the concentration of the complex in the thin film can be evaluated. In addition, the effect of solvent polarity on the complexation properties was examined in various $\mathrm{CHCl}_{3}: \mathrm{MeOH}$ solvent mixtures.

As expected the complexation process of $\mathrm{Na}^{+}$or $\mathrm{K}^{+}$is facilitated by using nonaqueous solvent mixtures containing chloroform (Table 5) because the constants of complexation are higher than in aqueous solvent (see later), and the diffusion of organic solvent into the hydrophobic matrix is probably more favorable. Subsequently, the decomplexation process can be followed by the disappearance of the $v(\mathrm{C} \equiv \mathrm{N})$ stretching band of thiocyanate incorporated in the layer. For the crown ether 1-PMHS95, the thiocyanate is completely removed by rinsing in aqueous mixture $\mathrm{MeOH}: \mathrm{H}_{2} \mathrm{O}$ (50:50) but not in pure 
$\mathrm{MeOH}$. This suggests that the complexation sites should be near the top of the surface to explain the facile decomplexation in aqueous solvent.

By comparison, the same experiments performed with 2-PMHS95 give lower values of $v(\mathrm{C} \equiv \mathrm{N})$ absorbance of less than 0.005 in $96 \%$ choroform mixture; subsequently, the decomplexation is readily done by rinsing the sample with pure $\mathrm{MeOH}$. These results indicate that in nonaqueous solvents, the anion-complexing properties of the urea group are negligible by comparison with the cation-complexing properties of the crown ether macrocycle in 1-PMHS95.

To explain the effect of solvent polarity on the cation-complexing properties of 1-PMHS95 in Table 5, some values of complexation constants $\left(\log _{10} K\right)$ for cation-macrocycle interaction of the 1:1 type are listed in Table 6. The association constant $(K)$ for benzo-15-crown-5 increases by several order of magnitude from aqueous to nonaqueous solvents such as methanol and chloroform. ${ }^{38}$ Indeed, the highest $K$ value of $10^{6} \mathrm{~mol}^{-1} . \mathrm{L}$ is found for chloroform, $K$ decreases then by about a factor $10^{3}$ for pure methanol, and $10^{6}$ for pure water (Table 6). Therefore, we assumed that a complete reaction occurred between the cation $\mathrm{M}^{+}$and the ligand $\mathbf{1}$ to form a complex $\mathrm{M}^{+}: \mathbf{1}$ of the $1: 1$ type by diffusion-reaction of the salt in the organic layer when chloroform mixtures are used. This is confirmed in Table 5 by a progressive increase of absorbance values from 50:50 to $96: 4 \mathrm{CHCl}_{3}: \mathrm{MeOH}$ mixtures.

The maximum absorbance found for $\mathrm{Na}^{+}$(Table 5) was then used to estimate the concentration of 1: $\mathrm{Na}^{+} \mathrm{SCN}^{-}$complex by applying the Beer-Lambert law for the $v(\mathrm{C} \equiv \mathrm{N})$ stretching band. It follows that $\left[1: \mathrm{Na}^{+}\right]=2.3 \mathrm{M}$ by taking the $v(\mathrm{C} \equiv \mathrm{N})$ extinction coefficient $\varepsilon_{\mathrm{C} \equiv \mathrm{N}}$ of $200 \mathrm{M} . \mathrm{cm}^{-1}$, the measured film thickness of $1 \mu \mathrm{m}$, and the maximum absorbance value of 0.046 for $\mathrm{Na}^{+}$. This concentration is about $10^{3}$ times higher than the starting concentration of the NaSCN solution $(1 \mathrm{mM})$ indicating that the diffusion of NaSCN salt in the layer is readily controlled by the complexation reaction with the ligand $\mathbf{1}$ immobilized in the polysiloxane matrix. The concentration of SiH groups in the starting PMHS95 matrix is equal to about $17 \mathrm{M}$ assuming the density of the PMHS95 layer is about $1 \mathrm{~g} / \mathrm{mL}$ and $M_{\text {PMHS95 }}=$ $59.07 \mathrm{~g} / \mathrm{mol}$. Then, by assuming an homogeneous distribution of $\mathbf{1}$ in the PMHS matrix, the 
concentration of the free ligand [1] of $2.5 \mathrm{M}$ can be obtained by multiplying the starting $\mathrm{SiH}$ concentration $(17 \mathrm{M})$ and the ratio of functionalization $\operatorname{SiC}(0.15)$ as measured by IR spectroscopy following hydrosilylation with 1 (Table 1). The various concentrations [1] (2.5 M) and [1: $\left.\mathrm{Na}^{+}\right](2.3 \mathrm{M})$ measured independently by two different methods are in good agreement which validates the aforementioned hypothesis. Further experiments should be undertaken to determine the distribution of the species in the layer.

\section{CONCLUSION}

Both the allyl urea precursors $\mathbf{1}$ and $\mathbf{2}$ were covalently immobilized via Pt-catalyzed hydrosilylation within lightly $\mathrm{T}^{\mathrm{H}}$-crosslinked PMHS networks prepared by sol-gel polycondensation of DH/TH mixtures of silicon hydride alkoxide precursors. The structure of the newly-formed crown ether matrix 1-PMHS95 and 2-PMHS95 as thin films was confirmed by FT-IR spectroscopy. The solid-state NMR spectra of 2-PMHS95 as powder clearly demonstrates the addition of the allyl urea precursor to $\mathrm{SiH}$ bonds following hydrosilylation. Based on a quantitative analysis of IR spectra of thin films, we have determined that the degree of crosslinking of the newly-formed polysiloxane matrix increases during the course of the hydrosilylation reactions because a part of the $\mathrm{SiH}$ groups undergoes a Pt-catalyzed hydrolysis by diffusion of water molecules. These side-reactions are significant because the presence of a heteroatom other than oxygen such as the amido group of urea precursors probably deactivates the platinum catalyst, and inhibits the primary hydrosilylation. We showed that the network reactivity is related to the mesh size of the starting PMHS network, and the facility of diffusion of alkenes or water molecules. We obtained the highest $\mathrm{SiH}$ conversion and ratio of functionalization $\mathrm{SiC}$ for the lowest crosslinked PMHS99 network prepared in this study. IR spectroscopy showed that strong intermolecular association of the urea groups by hydrogen bonding $\mathrm{NH} . . \mathrm{O}=\mathrm{C}$ occurs in polymer matrix. The newlyformed crown ether functionalized PMHS thin films showed effective complexation of $\mathrm{Na}^{+}$and $\mathrm{K}^{+}$ alkali metal in nonaqueous solvents which is a prerequisite for applications. 


\section{Acknowledgement}

The authors thank P. Déjardin for his comments about the manuscript, and E. Petit for liquid NMR and mass spectrometry experiments. The authors also acknowledge support from the CNRS.

\section{REFERENCES AND NOTES}

1. Helmy, R.; Wenslow, R. W.; Fadeev, A. Y. J Am Chem Soc 2004, 126, 7595-7600.

2. Luzinov, I.; Minko, S.; Tsukruk, V. V. Prog Polym Sci 2004, 29, 635-698.

3. Murata, H.; Chang, B. J.; Prucker, O.; Dahm, M.; Ruhe, J. Surf Sci 2004, 570, 111-118.

4. Schmatko, T.; Hervet, H.; Leger, L. Langmuir 2006, 22, 6843-6850.

5. Ulbricht, M. Polymer 2006, 47, 2217-2262.

6. Pluedemann, E. P. Silane Coupling Agents; Plenum Press: New York, 1982.

7. Ulman, A. Chem Rev 1996, 96, 1533-1554.

8. Thami, T.; Bresson, B.; Fretigny, C. J Appl Polym Sci 2007, 104, 1504-1516.

9. Thami, T.; Nasr, G.; Bestal, H.; Van der Lee, A.; Bresson, B. J Polym Sci Part A: Polym Chem 2008, $46,3546-3562$

10. Gadda, T. M.; Kus, E.; Mansfeld, F.; Finlay, J. A.; Callow, J. A.; Callow, M. E.; Kowalke, G. L.; Wendt, D. E.; Weber, W. P. J Polym Sci Part A: Polym Chem 2006, 44, 2237-2247.

11. Kolel-Veetil, M. K.; Keller, T. M. J Polym Sci Part A: Polym Chem 2006, 44, 147-155.

12. Gualandris, V.; Babonneau, F.; Janicke, M. T.; Chmelka, B. F. J Sol-Gel Sci Technol 1998, 12, 7580 .

13. Loy, D. A.; Baugher, B. M.; Baugher, C. R.; Schneider, D. A.; Rahimian, K. Chem Mater 2000, 12, 3624-3632.

14. Cordoncillo, E.; Viana, B.; Escribano, P.; Sanchez, C. J Mater Chem 1998, 8, 507-509.

15. Lukevics, E.; Belyakova, Z. V.; Pomerantseva, M. G.; Voronkov, M. G. J Organomet Chem Libr 1977, 5, 1-179.

16. Speier, J. L. Adv Organomet Chem 1979, 17, 407-447.

17. Stein, J.; Lewis, L. N.; Gao, Y.; Scott, R. A. J Am Chem Soc 1999, 121, 3693-3703.

18. Sandoval, J. E.; Pesek, J. J. Anal Chem 1991, 63, 2634-2641. 
19. Sandoval, J. E.; Pesek, J. J. Anal Chem 1989, 61, 2067-2075.

20. Ketelson, H. A.; Brook, M. A.; Pelton, R. H. Chem Mater 1995, 7, 1376-1383.

21. Suhara, T.; Kanemaru, T.; Fukui, H.; Yamaguchi, M. Colloids Surf A: Physicochem Eng Aspects $1995,95,1-9$.

22. Suhara, T.; Kutsuna, H.; Fukui, H.; Yamaguchi, M. Colloid Polym Sci 1993, 271, 486-493.

23. Olander, B.; Wirsen, A.; Albertsson, A. C. Biomacromolecules 2003, 4, 145-148.

24. Olander, B.; Wirsen, A.; Albertsson, A. C. Biomacromolecules 2002, 3, 505-510.

25. Chen, H.; Zhang, Z.; Chen, Y.; Brook, M. A.; Sheardown, H. Biomaterials 2005, 26, 2391-2399.

26. Cazacu, A.; Tong, C.; van der Lee, A.; Fyles, T. M.; Barboiu, M. J Am Chem Soc 2006, 128, 95419548.

27. Barboiu, M.; Cerneaux, S.; van der Lee, A.; Vaughan, G. J Am Chem Soc 2004, 126, 3545-3550.

28. Barboiu, M. J Incl Phenom Macrocycl Chem 2004, 49, 133-137.

29. Calderón, V.; García, F.; de la Peña, J. L.; Maya, E. M.; Lozano, Á. E.; de la Campa, J. G.; de Abajo, J.; García, J. M. J Polym Sci Part A: Polym Chem 2006, 44, 4063-4075.

30. Altintas, O.; Yilmaz, I.; Hizal, G.; Tunca, U. J Polym Sci Part A: Polym Chem 2006, 44, 3242-3249.

31. Alexandratos, S. D.; Stine, C. L. React Func Polym 2004, 60, 3-16.

32. Tang, X.-H.; Tan, S.-Y.; Wang, Y.-T. J Appl Polym Sci 2002, 83, 1886-1891.

33. Price, G. J.; Drake, P. L. Sens Actuators, B 2006, 114, 466-472.

34. Drake, P. L.; Price, G. J. Polym Int 2000, 49, 926-930.

35. Rowland, R. L.; Perry, W. L.; Gerstein, S. J Am Chem Soc 1951, 73, 3691-3693.

36. Lin-Vien, D.; Colthup, N. B.; Fateley, W. G.; Grasselli, J. G. The Handbook of Infrared and Raman Characteristic Frequencies of Organic Molecules; Academic Press: Boston, 1991.

37. Jadzyn, J.; Stockhausen, M.; Zywucki, B. J Phys Chem 1987, 91, 754-757.

38. Izatt, R. M.; Pawlak, K.; Bradshaw, J. S.; Bruening, R. L. Chem Rev 1991, 91, 1721-2085. 


\section{FIGURE CAPTIONS}

Figure 1 Chemical synthesis and structures of allyl urea derivatives $\mathbf{1}$ and $\mathbf{2}$.

Figure 2 Transmission infrared spectra of (a) reacted sample 1-PMHS95 (thin film) after hydrosilylation, and its precursors, (b) unreacted sample PMHS95 (thin film), same scale as (a), and (c) allyl urea $\mathbf{1}$ (in $\mathrm{KBr}$ ).

Figure 3 Transmission infrared spectra of (a) reacted sample 2-PMHS95 (thin film) after hydrosilylation, and its precursors, (b) unreacted sample PMHS95 (thin film), same scale as (a), and (c) allyl urea 2 (in $\mathrm{KBr}$ ).

Figure $4{ }^{29}$ Si NMR MAS spectra of (a) functionalized 2-PMHS95 and (b) starting PMHS95 as powders. Single-pulse experiment was done with proton decoupling, 500 scans accumulation. 


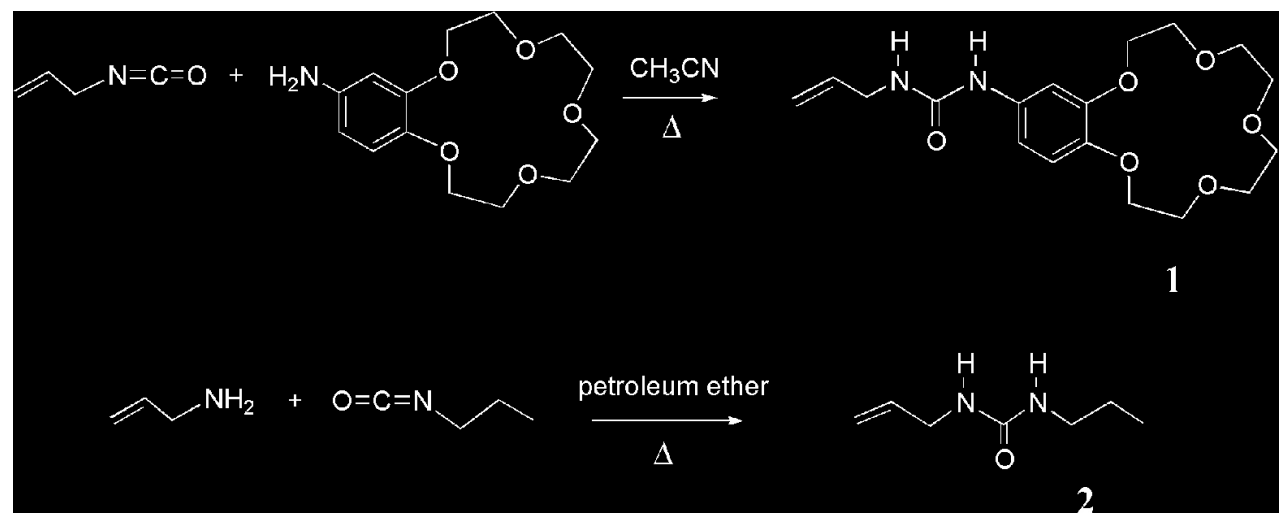

Figure 1. Chemical synthesis and structures of allyl urea derivatives 1 and 2. $163 \times 64 \mathrm{~mm}(300 \times 300 \mathrm{DPI})$ 


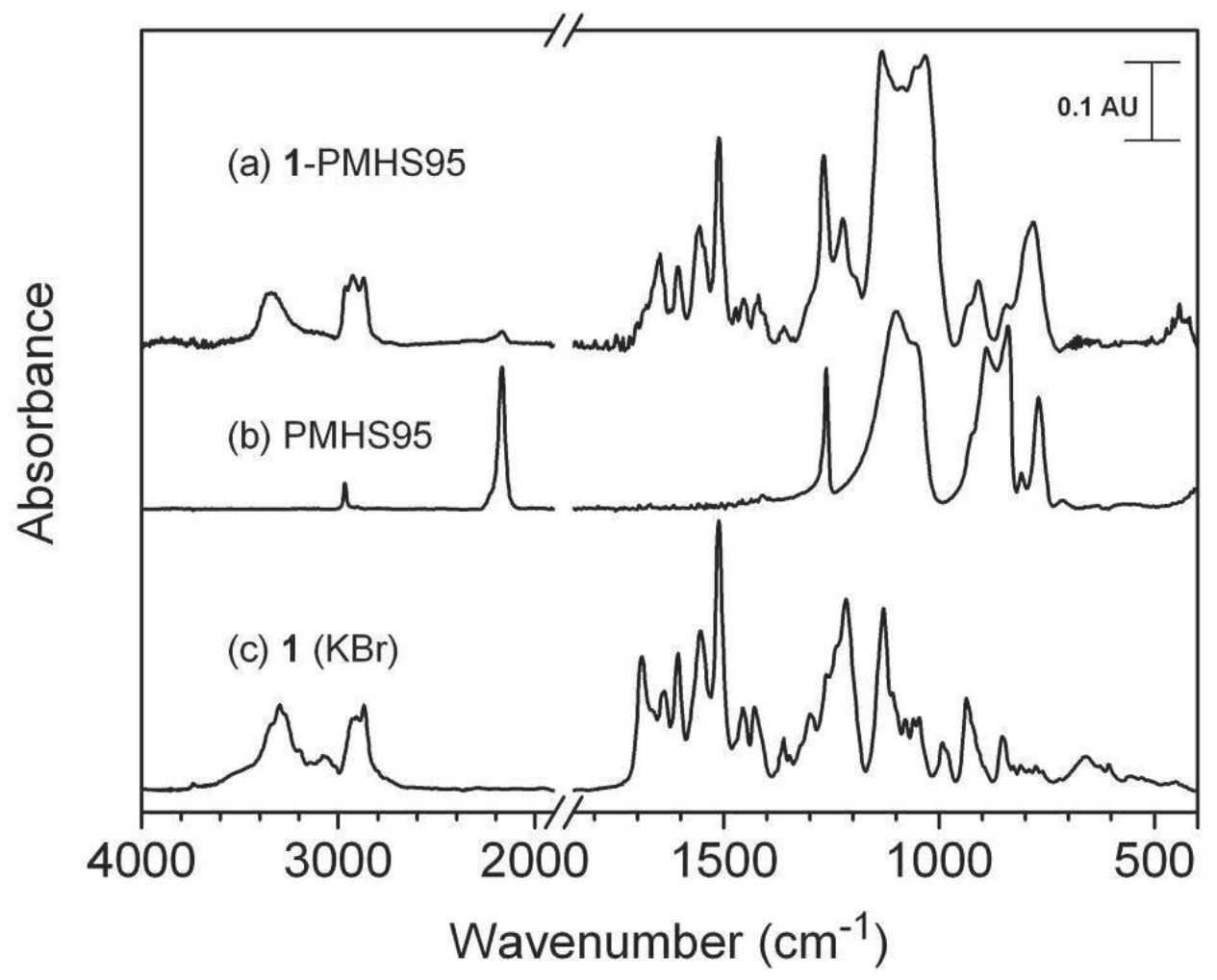

Figure 2. Transmission infrared spectra of (a) reacted sample 1-PMHS95 (thin film) after hydrosilylation, and its precursors, (b) unreacted sample PMHS95 (thin film), same scale as (a), and (c) allyl urea 1 (in $\mathrm{KBr}$ ). $80 \times 65 \mathrm{~mm}(300 \times 300 \mathrm{DPI})$ 


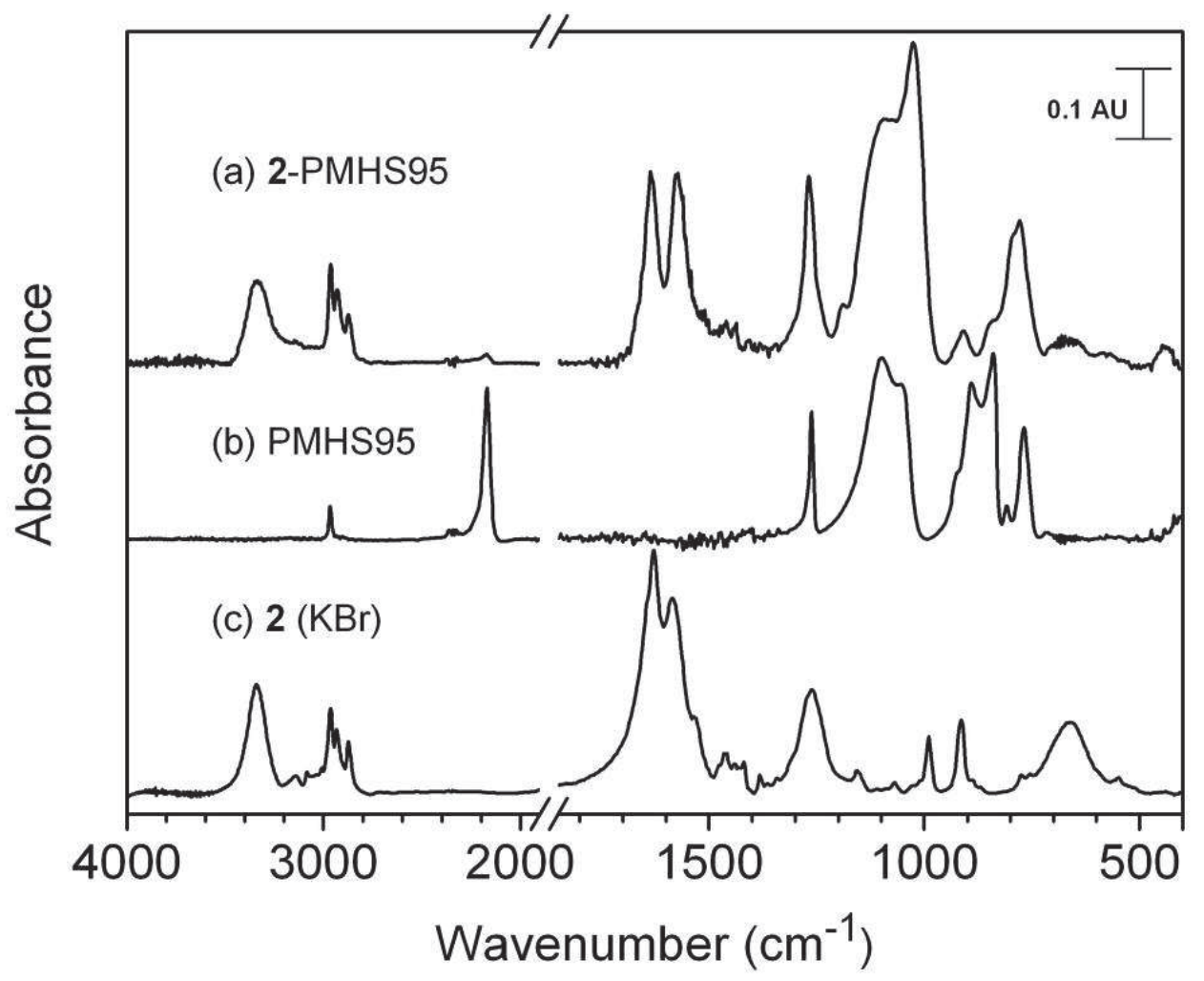

Figure 3. Transmission infrared spectra of (a) reacted sample 2-PMHS95 (thin film) after hydrosilylation, and its precursors, (b) unreacted sample PMHS95 (thin film), same scale as (a), and (c) allyl urea 2 (in $\mathrm{KBr}$ ). $80 \times 65 \mathrm{~mm}(300 \times 300 \mathrm{DPI})$ 

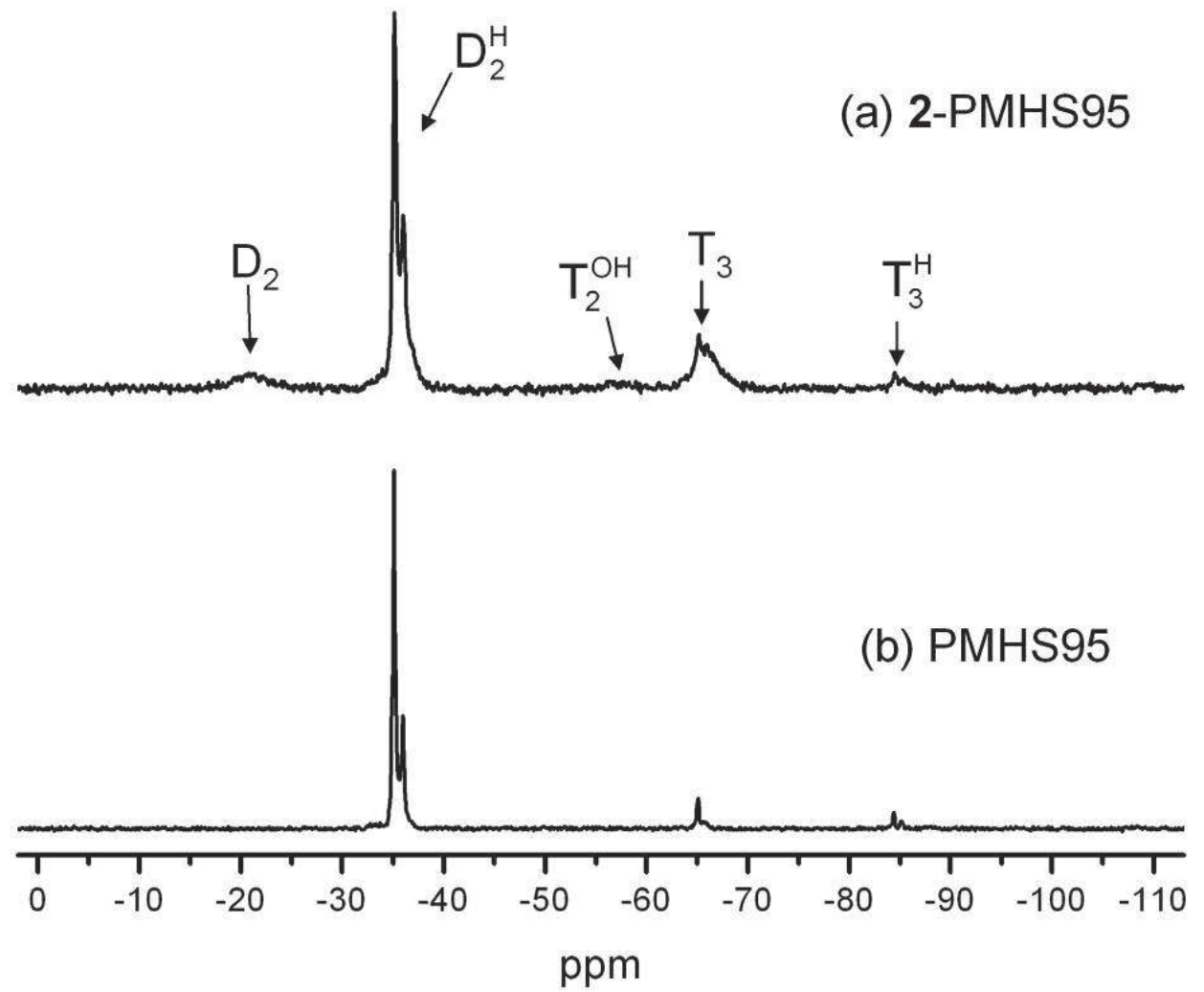

Figure 4. ${ }^{29}$ Si NMR MAS spectra of (a) functionalized 2-PMHS95 and (b) starting PMHS95 as powders. Single-pulse experiment was done with proton decoupling, 500 scans accumulation.

$80 \times 67 \mathrm{~mm}(300 \times 300 \mathrm{DPI})$ 
TABLE I

$\mathrm{SiH}$ Residual (\%), SiC Functionalization (\%), and New Crosslink Formation (\%) after Hydrosilylation of the Lightly $\mathrm{T}^{\mathrm{H}}$-Crosslinked PMHS Networks with Allyl Urea Compounds 1 and 2

\begin{tabular}{cccc}
\hline PMHS Substrate & SiH (\%) & SiC (\%) & New Crosslinks (\%) \\
\hline 1-PMHS (thin-film) ${ }^{\mathrm{a}}$ & 10 & 15 & 75 \\
PMHS95 & & & 55 \\
2-PMHS (thin-film) & a & 45 & 65 \\
PMHS99 & $\sim 0$ & 30 & 65 \\
PMHS95 & 5 & 5 & 15 \\
PMHS85 & 30 & & \\
2-PMHS (powder) & & 11 & \\
PMHS95 & 66 & & \\
\hline
\end{tabular}

${ }^{a}$ For thin films $(\sim 1 \mu \mathrm{m}), \mathrm{SiH}$ residual, and $\mathrm{SiC}$ functionalization (\%) based on IR absorption measurements of $v(\mathrm{SiH})$ and $v_{a s}\left(\mathrm{CH}_{2}\right)$ stretching bands, respectively (see Experimental section), and formation of new crosslinks $(\%)=100 \%-\mathrm{SiH}(\%)-\mathrm{SiC}(\%)$, by assuming Pt catalyzed $\mathrm{SiH}$ hydrolysis and coupling reaction between $\mathrm{SiH} / \mathrm{SiOH}$.

${ }^{\mathrm{b}}$ For powder, $\mathrm{SiH}, \mathrm{SiC}$, and formation of new crosslinks (\%) measured by quantitative solid-state ${ }^{29} \mathrm{Si}$ MAS NMR (see Table 4). Particles size of powders $10-150 \mu \mathrm{m}$. 
TABLE II

Infrared Peak Assignments of Functionalized 1-PMHS95 (thin film), Virgin PMHS95 (thin film), and Pure Substance 1 (Kbr)

\begin{tabular}{|c|c|c|c|}
\hline \multirow{2}{*}{ Group Frequency ${ }^{\S}$} & \multicolumn{3}{|c|}{ Band Position $\left(\mathrm{cm}^{-1}\right)$} \\
\hline & $\begin{array}{l}\text { 1-PMHS95 } \\
\text { (thin film) }\end{array}$ & $\begin{array}{c}1 \\
(\mathrm{KBr})\end{array}$ & $\begin{array}{l}\text { PMHS95 } \\
\text { (thin film) }\end{array}$ \\
\hline$v(\mathrm{NH})($ free $)$ & 3400-3500 sh & $\sim 3400-3500 \mathrm{sh}$ & \\
\hline$v(\mathrm{NH})($ associated $)$ & $\sim 3340$ & $\begin{array}{l}3340 \text { sh, } 3299 \\
3275 \text { sh, } 3199\end{array}$ & \\
\hline$v_{\text {as }}\left(\mathrm{CH}_{2}\right)_{\text {allyl }}$ & & 3078 & \\
\hline$v_{s}\left(\mathrm{CH}_{2}\right)_{\mathrm{allyl}}+v(\mathrm{CH})_{\text {allyl }}$ & & 3010 & \\
\hline$v_{a s}\left(\mathrm{CH}_{3}\right)$ & 2962 & & 2966 \\
\hline$v_{a s}\left(\mathrm{CH}_{2}\right)$ & 2929 & 2929, 2907 & \\
\hline$v_{s}\left(\mathrm{CH}_{2}\right)$ & 2872 & 2870 & \\
\hline$v(\mathrm{SiH})$ & 2168 & & 2169 \\
\hline$v(\mathrm{C}=\mathrm{O})$ (amide $\mathrm{I}$, free $)$ & $\sim 1680$ & 1690 & \\
\hline$v(\mathrm{C}=\mathrm{O})$ (amide $\mathrm{I}$, associated) & 1647 & $1638,1660 \mathrm{sh}$ & \\
\hline$v(\mathrm{C}=\mathrm{C})_{\text {allyl }}$ & & 1640-1650 sh* & \\
\hline$v(\mathrm{C}=\mathrm{C})_{\text {aromatic }}$ & 1607 & 1606 & \\
\hline$\delta(\mathrm{NH})$ (amide II) & 1556,1511 & 1553,1512 & \\
\hline$\delta\left(\mathrm{CH}_{2}\right)$ & 1453 & 1455 & \\
\hline$\delta_{a s}\left(\mathrm{SiCH}_{3}\right)$ & & & $\sim 1410$ \\
\hline$\delta_{s}\left(\mathrm{SiCH}_{3}\right)$ & 1268 & & 1262 \\
\hline$v(\mathrm{CN})$ (amide III) & 1223 & $1299,1261,1216$ & \\
\hline$v_{a s}(\mathrm{COC})_{\text {crown ether }}$ & 1133 & 1129 & \\
\hline$v_{a s}(\mathrm{SiOSi})$ & 1032 & & $1100,1055 \mathrm{sh}$ \\
\hline$\delta(\mathrm{CH})_{\text {allyl }}$ (out-of-plane) & & 993 & \\
\hline$\delta(\mathrm{SiH})$ (scissoring) & & & 891,840 \\
\hline$\delta\left(\mathrm{CH}_{3}\right)\left(\right.$ rocking in $\left.\mathrm{SiCH}_{3}\right)$ & 781 & & 769 \\
\hline
\end{tabular}

${ }^{\S}$ Abbreviations: sh, shoulder; $v$, stretching mode; as, asymmetric; s, symmetric; $\delta$, bending mode. $* v(\mathrm{C}=\mathrm{C})_{\text {allyl }}$ peak is covered by stronger peak of $v(\mathrm{C}=\mathrm{O})$ at $1638 \mathrm{~cm}^{-1}$. 


\section{TABLE III}

Infrared Peak Assignments of Functionalized 2-PMHS95 (thin film)

and Pure Substance 2 (KBr)

\begin{tabular}{|c|c|c|}
\hline \multirow[b]{2}{*}{ Group Frequency $^{\S}$} & \multicolumn{2}{|c|}{ Band Position $\left(\mathrm{cm}^{-1}\right)$} \\
\hline & $\begin{array}{l}\text { 2-PMHS95 } \\
\text { (thin film) }^{¥}\end{array}$ & $\begin{array}{c}2 \\
(\mathrm{KBr})\end{array}$ \\
\hline$r(\mathrm{NH})$ (associated) & $3340, \sim 3140$ & 3342,3140 \\
\hline$v_{a s}\left(\mathrm{CH}_{2}\right)_{\mathrm{ally}}$ & & 3084 \\
\hline$v_{s}\left(\mathrm{CH}_{2}\right)_{\mathrm{allyl}}+v(\mathrm{CH})_{\mathrm{allyl}}$ & & 3009 \\
\hline$v_{a s}\left(\mathrm{CH}_{3}\right)$ & 2964 & 2964 \\
\hline$v_{a s}\left(\mathrm{CH}_{2}\right)$ & 2931 & 2934 \\
\hline$v_{s}\left(\mathrm{CH}_{2}\right)$ & 2874 & 2875 \\
\hline$v(\mathrm{SiH})$ & 2173 & \\
\hline$v(\mathrm{C}=\mathrm{O})$ (amide $\mathrm{I}$, associated) & 1636 & 1628 \\
\hline$v(\mathrm{C}=\mathrm{C})_{\mathrm{allyl}}$ & & 〜 1640-1650 sh* \\
\hline$\delta(\mathrm{NH})$ (amide II) & 1572 & 1585,1535 \\
\hline$\delta\left(\mathrm{CH}_{2}\right)$ & 1460 & 1465 \\
\hline$\delta(\mathrm{CH})_{\mathrm{allyl}}$ & & 1419 \\
\hline$\delta_{s}\left(\mathrm{SiCH}_{3}\right)$ & 1268 & \\
\hline$v(\mathrm{CN})$ (amide III) & $\sim 1300-1250 \mathrm{sh}^{* *}$ & 1261 \\
\hline$v_{a s}(\mathrm{SiOSi})$ & $1100 \mathrm{sh}, 1025$ & \\
\hline$\delta(\mathrm{CH})_{\text {allyl }}$ (out-of-plane) & & 990,914 \\
\hline$\delta\left(\mathrm{CH}_{3}\right)$ (rocking in $\left.\mathrm{SiCH}_{3}\right)$ & 778 & \\
\hline
\end{tabular}

${ }^{\S}$ Abbreviations: same as Table 2.

${ }^{\sharp}$ Virgin PMHS95 (thin film) as given in Table 2.

$* v(\mathrm{C}=\mathrm{C})_{\text {allyl }}$ peak is covered by stronger peak of $v(\mathrm{C}=\mathrm{O})$ at $1628 \mathrm{~cm}^{-1}$.

** $v(\mathrm{CN})$ stretching is covered by sharper peak of $\mathrm{SiCH}_{3}$ at $1268 \mathrm{~cm}^{-1}$. 


\section{TABLE IV}

Quantitative ${ }^{29}$ Si MAS Analysis of the Functionalized 2-PMHS95 Obtained by Hydrosilylation and Starting PMHS95 as Powders after Grinding the Gel Structure

\begin{tabular}{|c|c|c|c|c|c|c|c|c|c|c|}
\hline \multirow[b]{2}{*}{ Powders* } & \multicolumn{2}{|c|}{$\mathrm{D}_{2}$} & \multicolumn{2}{|c|}{$\mathrm{D}_{2}{ }^{\mathrm{H}}$} & \multicolumn{2}{|c|}{$\mathrm{T}_{2}{ }^{\mathrm{OH}}$} & \multicolumn{2}{|c|}{$\mathrm{T}_{3}$} & \multicolumn{2}{|c|}{$\mathrm{T}_{3}{ }^{\mathrm{H}}$} \\
\hline & $\delta$ & $\%$ & $\delta$ & $\%$ & $\delta$ & $\%$ & $\delta$ & $\%$ & $\delta$ & $\%$ \\
\hline \multirow[t]{2}{*}{ PMHS95 } & & & -35.1 & 87.3 & & & -65.1 & 7.4 & -84.4 & 5.2 \\
\hline & & & -36.0 & & & & & & -85.1 & \\
\hline \multirow[t]{2}{*}{ 2-PMHS95 } & -21.2 & 9.2 & -35.1 & 63.3 & $\approx-57$ & 2.1 & -65.2 & 22.5 & -84.4 & 2.9 \\
\hline & & & -36.0 & & & & & & -85.1 & \\
\hline
\end{tabular}

*Particles size of the powders $10-150 \mu \mathrm{m}$. 


\section{TABLE V}

Absorbance of the $v(\mathrm{C} \equiv \mathrm{N})$ Stretching Band of Thiocyanate Salts Incorporated in 1-PMHS95 Layer $(1 \mu \mathrm{m})$ at $2054 \mathrm{~cm}^{-1}$ for $\mathrm{KSCN}$ and $2059 \mathrm{~cm}^{-1}$ for $\mathrm{NaSCN}$

\begin{tabular}{|c|c|c|}
\hline \multirow{2}{*}{$\begin{array}{c}\text { Solvent } \\
\mathrm{CHCl}_{3}: \mathrm{MeOH} \\
\text { (v:v) }\end{array}$} & \multicolumn{2}{|c|}{ Absorbance $v(\mathrm{C} \equiv \mathrm{N})$} \\
\hline & $\mathrm{Na}^{+}$ & $\mathrm{K}^{+}$ \\
\hline $96: 4$ & 0.046 & 0.031 \\
\hline $90: 10$ & 0.032 & 0.033 \\
\hline $50: 50$ & 0.006 & 0.011 \\
\hline
\end{tabular}




\section{TABLE VI}

Selected Values of the Logarithm of the Association Constant $\left(\log _{10} K\right)$ in Aqueous and Nonaqueous Solutions for Benzo-15-crown-5 and Alkali Metal Cations $\left(\mathrm{Na}^{+}\right.$and $\mathrm{K}^{+}$) from Izatt et $\mathrm{al}^{38}$ and Reference Herein

\begin{tabular}{cccc}
\hline & \multicolumn{2}{c}{$\log _{10} K^{*}$} \\
\cline { 2 - 2 } Solvent & $\mathrm{Na}^{+}$ & $\mathrm{K}^{+}$ \\
\hline $\mathrm{CDCl}_{3}$ & 6.26 & & 5.90 \\
$\mathrm{MeOH}$ & 2.99 & & 2.71 \\
$\mathrm{H}_{2} \mathrm{O}$ & -0.21 & & -0.05 \\
\hline
\end{tabular}

$* K\left(\mathrm{~mol}^{-1}\right.$.L) corresponds to the first step of complexation for cation-macrocycle interactions of the 1:1 type as follows:

$$
\begin{gathered}
\mathrm{M}^{+}+\mathrm{L} \rightleftharpoons \mathrm{LM}^{+} \\
K=\frac{\left[L M^{+}\right]}{\left[M^{+}\right][L]}
\end{gathered}
$$

where $\mathrm{L}=$ Macrocyclic ligand and $\mathrm{M}^{+}=$Metal ion 